\title{
The Economics and Ethics of Markets for Human Organs
}

\author{
Henry Hansmann, Yale University
}

\begin{abstract}
In 1984, federal legislation outlawing payment for human organs for transplantation was adopted after only cursory discussion of the underlying policy issues. More considered analysis suggests that this prohibition may be overly broad. It appears possible to design suitably regulated market-type approaches to the acquisition and allocation of cadaveric organs (and perhaps of organs from living donors as well) that will be neither unduly offensive to ethical sensibilities nor easily abused and that may yield significant improvements over the existing system of organ procurement, which presents important ethical and practical problems of its own. Moreover, whatever ultimate judgment we reach concerning the merits of markets for transplantable organs, analysis of the sources of the initial moral resistance to the commercialization that lies behind measures such as the 1984 legislation offers insights into the respective roles of market and nonmarket institutions in general.
\end{abstract}

Recent advances in the technology for transplanting human organs have led to a large increase in the demand for suitable organs. As a consequence, demand now considerably exceeds supply (U.S. DHHS 1986; Lee 1986). This situation gives rise to two policy problems: First, can we and should we increase the overall supply of organs? Second, how should we allocate the existing scarce supply among the many individuals who would benefit from a transplant? In the United States, markets are the conventional mechanisms used to deal with both of these issues for most goods and services. At present, however, federal law (as well as the laws of many states) prohibits the commercial sale of organs and thus rules out market solutions to problems of organ study and distribution.

In this essay I will analyze the advantages and disadvantages of markets for human organs, explore the ways in which such markets might be organized and regulated, and assess the wisdom of the statutes that outlaw such markets. The subject, which is complicated in any event, is rendered even more difficult because it is heavily fraught with strong moral sentiments. To many individuals, the notion of employing markets in such a setting is deeply disturbing. I will take these moral

\footnotetext{
The author is grateful to participants in the Conference on Organ Transplantation Policy, Vanderbilt Institute for Public Policy Studies, Vanderbilt University, 26-28 June 1988 for stimulating discussion. The author also thanks James Blumstein, Katherine Durso, Jay Katz, Susan Rose-Ackerman, Peter Schuck, and Alan Schwartz for helpful comments on an earlier draft.
}

Journal of Health Politics, Policy and Law, Vol. 14, No. 1, Spring 1989. Copyright @ 1989 by Duke University. 
concerns seriously here. In particular, I will ask whether it is possible to design compensation schemes that are not strongly antithetical to our ethical intuitions. But beyond this, I will also explore why it is that these intuitions (at least initially) often run so strongly counter to the notion of paying compensation for transplantable organs.

Whatever our initial sentiments, we have an obligation as a society to inquire seriously into these difficult issues. Each year many thousands of lives are lost for lack of transplantable organs and hundreds of millions of dollars are spent on the existing transplant system ${ }^{1}$ - and these figures are likely to increase significantly in the future. We cannot afford to reject any approach that would increase the supply of organs or improve the efficiency with which organs are allocated and transplanted without the most thoughtful consideration. Moreover, careful analysis of this subject promises to illuminate other areas where prohibition of commercial sales is currently a topic of serious debate, such as adoption ${ }^{2}$ and surrogate motherhood.

\section{The Current Legal Regime}

Historically, the common law did not provide anyone with a clear property right in a human corpse, and thus did not give anyone the authority to transfer a cadaver or any of its parts for any purpose by gift or sale (Vestal et al. 1954). ${ }^{3}$ Thus when transplants first became feasible, there was no legal mechanism whereby individuals could designate that their organs could be used for transplants upon death. To rectify this situation, the Uniform Anatomical Gift Act (UAGA) was promulgated in 1968 and adopted in some form in every state by 1973 (Michigan Law Review 1974). The UAGA explicitly gives individuals the right to designate prior to death whether their bodies or organs are to be donated for transplants. In cases where a decedent's wishes are not known, the act gives the next of kin the right to designate whether or not organs are to be donated.

The UAGA deals expressly only with donations of organs; it is silent on the subject of sales. According to the chairman of the committee that drafted the UAGA, it was intended neither to encourage nor to discourage remuneration: " . . . it is possible, of course, that abuses may occur if payment could customarily be demanded, but every payment is not necessarily unethical. . . . Until the matter of payment becomes a problem of some dimensions, the matter should be left to the decency of intelligent human beings" (Stason 1968: 928).

1. In 1985 , the Medicare program paid $\$ 285$ million for kidney transplants alone (Schuck 1989).

2. See Landes and Posner (1978), Prichard (1984), and Boston University Law Review (1987).

3. This does not mean that sales or gifts were illegal, but only that contracts for sale or deeds of gift were not enforceable at law. 


\section{Hansmann - Markets for Human Organs}

In the 1960s (prior to the adoption of the UAGA) some states adopted statutes explicitly prohibiting the sale of human bodies and organs. Most of these states repealed such statutes when they adopted the UAGA. ${ }^{4}$ It is unclear whether these repeals were simply the result of a program of repealing all relevant statutes predating the UAGA or whether they reflected a judgment that the prohibitions on sales were either overridden by the UAGA or, conversely, made redundant by it. In any event, Delaware evidently did not hold the latter view, since it added an explicit prohibition on sales to its version of the UAGA. ${ }^{5}$

The status of the sale of organs for transplantation therefore remained uncertain until Congress adopted the National Organ Transplant Act (NOTA) in 1984. NOTA was essentially an effort to enhance the system of voluntary provision of transplantable organs contemplated by the UAGA. Its principal provisions established federal financial support for local nonprofit organ procurement organizations and for a national organ procurement and transplantation network to assist in matching organ donors and recipients. However, NOTA also effectively outlawed commercial markets in transplantable organs by making it a federal crime "for any person to knowingly acquire, receive, or otherwise transfer any human organ for valuable consideration for use in human transplantation if the transfer affects interstate commerce. ${ }^{6}$ Several states have subsequently supplemented this act with separate statutes of their own outlawing the sale or purchase of human organs. ${ }^{7}$ As a consequence, any effort to establish a market for organs today would require the repeal or amendment of legislation at both the federal and state levels.

Neither the federal nor the state legislation outlawing markets for organs were accompanied by careful policy analysis justifying the ban. NOTA did, however, establish the federal Task Force on Organ Procurement and Transplantation to inquire further into the policy issues raised by transplants. But when the task force submitted its report in 1986 it reaffirmed NOTA's ban on the commercialization of organ transplantation without further analysis, simply offering the conclusory observation that "society's moral values militate against regarding the body as a commodity" and suggesting that such a ban is appropriate to "encourage altruism" (U.S. DHHS 1986: 96). The task force also proceeded to encourage individual states to adopt their own prohibitions on the commercial sale of organs because NOTA, limited as it is to sales affecting interstate commerce, might not be entirely effective in suppressing such sales.

4. E.g., Law of Aug. 1, 1968, ch. 429, sec. 7, 56 Del. Laws 1773, 1773 (1967) (repealed 1970); Law of April 22, 1964, ch. 702, sec. 1, 1964 N.Y. Laws 1827, 1828 (repealed 1971); Act of June 12, 1967, ch. 353, 1967 Mass. Acts 202, 202 (repealed 1971).

5. Del. Code Ann. tit. $24 \S 1783$ (f) (1981).

6. 42 U.S.C. $\$ 274(\mathrm{e})(1982)$. The act specifies that its prohibition does not extend to payments made to cover costs incurred in the process of transplanting the organ.

7. These states include Virginia, Maryland, and California. For a partial survey see Virginia Law Review (1985). 


\section{0}

Journal of Health Politics, Policy and Law

In the discussion that follows I will seek to offer a more comprehensive analysis of NOTA's proscription of commercial sales. For this purpose it will be helpful to distinguish between the use of markets to encourage individuals to make their organs available for transplantation and the use of markets to allocate the available supply of organs among the individuals who wish to receive them. As Calabresi and Bobbitt (1978) have emphasized, in "tragic" contexts (such as life-saving organ transplants) it is entirely possible and often quite appropriate to use a market for one of these purposes and not the other. Consequently, I will consider these two different uses for markets in turn.

\section{Markets for Procuring Organs}

Some organs can be obtained from living donors. This is true of kidneys in particular, since most individuals can lose one of their two kidneys without serious impairment of their health. It appears that in banning commercial sales of organs, the authors of NOTA and of the similar state statutes were focusing particularly on sales by living donors, and especially on one notorious effort by a former Virginia doctor, whose license had previously been revoked for fraud, to establish a company to solicit living individuals (including indigents from the third world) to sell one of their kidneys for transplantation in transactions to be brokered by the company for a profit (Virginia Law Review 1985: 1020-22). Most transplantable organs, however, are "harvested" from cadavers, and indeed many organs, including livers, hearts, and lungs, can only be obtained from persons who are deceased. I will therefore focus first on markets for cadaveric organs, then turn to the issues raised by sales of organs from living donors.

\section{Markets for cadaveric organs}

Current estimates indicate that of the roughly 20,000 Americans who die annually under circumstances that would make their organs suitable for harvesting, only about 15 percent actually donate their organs. ${ }^{8}$ One important reason for this low donation rate is that relatively few individuals fill out and carry organ donor cards or otherwise indicate their willingness to donate their organs prior to death. ${ }^{9}$ And although under the UAGA the deceased's next of kin can authorize donation, attending physicians are understandably reluctant to press for such permission ${ }^{10}$ and families are often reluctant to give it, particularly under the difficult circum-

8. S. Rep. No. 769, 98th Cong., 2d Sess. 4 (1984); U.S. DHHS (1986: 35).

9. Polls indicate that only 17 percent of Americans have actually completed donor cards (Gallup Organization 1985). Presumably fewer actually carry such cards.

10. The primary obligation of the attending physician is, of course, to the patient and the patient's family, not to the potential recipient of the patient's organs. 
stances surrounding death. ${ }^{11}$ However, these low authorization rates evidently do not reflect widespread opposition to the idea of donating organs. Surveys indicate that more than 70 percent of Americans support the concept and express a general willingness to donate (Koop 1984).

These observations suggest that with some effort, donation rates might be increased substantially. Current policy proposals focus principally on three different types of measures that might be adopted for this purpose: (1) "required request," under which health care professionals would be required by law to ask the family of a deceased or dying person to donate the deceased's organs (U.S. DHHS 1986); (2) "presumed consent," under which organs would be assumed available for transplantation unless an objection had previously been registered, either by the decedent prior to death or by the next of kin at the time of death (Dukeminier and Sanders 1968); and (3) "mandated choice," under which all individuals over a certain age would be required by law to choose at some point-perhaps upon applying for a driver's license or for a social security card-whether or not to make their organs available for transplants upon their death (Katz 1984). There is reason to believe, however, that the first two of these policies do not promise a substantial increase in donation rates: required request statutes have already been adopted in at least 28 states, with only limited results (Gerson 1987), ${ }^{12}$ while presumed consent laws are in force in fourteen European countries, none of which have notably better donation rates than the United States. ${ }^{13}$ And the mandated choice approach, although holding some promise of a further increase in donation rates, has the disadvantage that in itself it provides no special incentives for people to choose in favor of donation. ${ }^{14}$ It is worth inquiring, therefore, whether offering compensation might lead to substantially higher donation rates without excessive offsetting disadvantages.

Feasible designs for a market. Before we can evaluate the desirability of having a market for organs, it is important that we have clearly in mind the particular forms that the market might take.

11. Moreover, even when the deceased has indicated an intention to donate, hospitals are generally unwilling to proceed unless the family also expresses agreement. (Interview with Frances Angeletti, transplant organ procurement coordinator, Department of Surgery, Yale-New Haven Hospital, 10 December 1987.)

12. A variant of the required request approach has now been imposed on all hospitals receiving funds under either Medicare or Medicaid by the Omnibus Budget Reconciliation Act of 1986, Pub. L. No. 99-509, § 1138, 100 Stat. 4599 (1986).

13. In practice, evidently even strict presumed consent laws are functionally equivalent to the prevailing American approach under which the approval of the next of kin is required (Gerson 1987).

14. The mandated choice approach also runs a risk similar to that presented by the insurance premium deduction scheme discussed below. If a substantial number of individuals were to choose not to donate, then presumably this choice would have to be respected upon their death, thus foreclosing the possibility of persuading their next of kin to donate their organs on their behalf. It is therefore possible that the mandated choice approach, absent any inducements to make the choice in favor of donation, could lead to a reduction in the overall rate of donation. 


\section{2} Journal of Health Politics, Policy and Law

Purchasing organs from dead people is obviously impossible. It also seems unwise to seek to purchase the rights to a person's organs while they are awaiting death: such transactions would often be traumatic for all concerned, and patients might be worried that if they agreed to sell, the care they received subsequently would be less than zealous. Moreover, since a large fraction of potentially harvestable organs come from people who die suddenly in accidents, such transactions would often be infeasible in any event. Seeking to purchase the right to remove a decedent's organs from the next of kin at the time of death is also a dubious policy: there is little time to arrange the transactions, and the transactions would be extremely awkward and often traumatic for the family members involved, who would have to decide under difficult emotional circumstances whether to accept a (potentially quite large) sum of money in return for something they (and others) might well feel is not theirs to sell. (This is not to say that serious proposals for such compensation have not been suggested. For example, it has been seriously proposed, even by individuals who express strong opposition in the abstract to the idea of compensating organ donors, that organ procurement agencies offer to pay funeral expenses for poor families if they will agree to donate the organs of a deceased relative. It has been suggested that this might be particularly helpful in encouraging donations among minorities, who evidently are often especially reluctant to donate because, among other things, they are suspicious that their deceased relative's organs will simply be used to help prosperous white people. Such a policy, which would clearly violate NOTA, is of course subject to the serious objection that it appears to patronize and exploit the groups to whom it is targeted.)

It therefore appears that the most feasible method for establishing a market in cadaveric organs would be to structure it as a futures market-that is, the right to harvest a person's organs upon death must be purchased from him while he is alive and well. (Although the term futures market may bring to mind misleadingly offensive images of hog bellies and the Chicago Commodities Exchange, I will nevertheless use the expression here for economy of reference. As I will try to make clear, a futures market for cadaver organs need look very little like the market for spring wheat.)

The most explicit proposal to date for such a futures market has been made by Schwindt and Vining (1986). ${ }^{15}$ They describe a system under which an individual would receive a current cash payment in exchange for the right to harvest their organs if they should die under circumstances in which their organs were transplantable. Schwindt and Vining seem to envisage that the resulting contract would be binding for the rest of the donor's life. They further propose that the government be made the sole purchaser of such rights. Upon examination, however, neither of these central features of their proposal seems necessary or desirable. There is no need for an individual to enter into a futures contract of lifetime duration; in

15. For another, much less detailed proposal, see Brams (1977). 


\section{Hansmann - Markets for Human Organs}

fact, annual contracts appear both feasible and preferable. Further, there is no need to make the government the sole purchaser. Schwindt and Vining support this latter aspect of their plan with the argument that the economies promised by a central clearing mechanism for matching donors and recipients make the organ procurement system a natural monopsony. Yet it is possible to have a centralized clearing system while still having multiple purchasers and holders of property rights in organs.

These points become clearer if we consider alternative approaches. One of the most promising alternatives is to make providers of health insurance the principal purchasers of future rights in organs. I will describe and analyze a scheme of this type in some detail here. There are also a number of other ways to purchase future rights in organs. For example, a bill was recently introduced in the Connecticut legislature calling for a refund of $\$ 10$ of the fee for the renewal of a driver's license for individuals who agree to donate their organs. ${ }^{16}$ Each such scheme has its particular advantages and disadvantages - and all are currently proscribed by NOTA. I will concentrate on the health insurance approach here, however, in order to provide a clear focus for my discussion.

A health insurance premium reduction plan. Health insurance companies would be natural purchasers of future rights to organs because these companies are already involved in the types of actuarial calculations and financial transactions that would be involved. Insurers might simply insert in their annual premium statements a provision (a check-off box would probably suffice) by means of which their policyholders could indicate that, in case they were to die during the period (generally the coming year) covered by the premium statement, the insurance company or its assignees would have the right to harvest any of the insured's organs that were transplantable. In return for checking this box, the insured would receive a specified reduction in their insurance premium for that period. Individuals would be free to change their mind about being a donor annually (or whenever their insurance policy was renewed). ${ }^{17}$

Each insurance company would submit to a central national registry the identification of each of its insureds who had chosen the donation option. Hospitals would then be required to check this national registry upon the death of any patient whose organs are potentially suitable for transplantation. ${ }^{18}$ If the patient were enrolled in the registry for the current year, the hospital would indicate which of the

16. Proposed bill no. 5456, Connecticut General Assembly, February session (1988).

17. In order to have the forces of inertia work in favor of organ donation (and also to avoid making insureds repeatedly confront a difficult issue), policy renewals could be structured to provide that once an individual had elected to donate in return for a premium reduction, that option would be automatically renewed unless the insured took some affirmative action to revoke it.

18. Hospitals might be required by governmental regulation to check the registry, or induced to do so either by offer of a payment for each registered transplantable organ they locate and/or by liability for failure to check the registry to determine the owner, if any, of the rights to the organs. 
patient's organs were available, and suitable recipients could be located through the national matching network. A recipient of one of the deceased's organs (or the recipient's health insurer) would then be obliged to pay the deceased's insurance company, or their assignee, the latter's stated price for an organ upon accepting it for transplant.

Group health insurance policies, which cover a substantial fraction of the nation's workforce, might deal with the problem of individual choice in several ways. One approach would be to provide that all workers under a given employer's plan will be presumed to agree to donate unless they complete a form indicating otherwise, in which case an additional payroll deduction would be made for their health insurance coverage. Such an approach-especially if combined with a promotional program sponsored by the employer, the union, and the local public health department stressing the social value of donation-might well assure very high levels of donation.

All types of health insurance companies - for-profit, nonprofit (Blue Cross/Blue Shield), and even governmental (Medicare/Medicaid) - could participate in such a scheme. The insurance companies would act primarily as intermediaries, purchasing and then reselling rights to harvest organs. Many insurance companies might choose to resell their futures contracts to other firms that would specialize in holding such contracts.

Institutions or individuals other than health insurance companies might also be permitted to solicit organ futures. One advantage of thus broadening the range of purchasers and holders of rights is that it might help bring within the system the roughly 13 percent of the population that is not currently covered by any form of private or public health insurance (U.S. Department of Commerce 1987) ${ }^{19}$ On the other hand, a disadvantage is that it would be more difficult to assure that all futures are purchased honestly and recorded accurately. Moreover, there might be a tendency for some firms to seek out and solicit organ futures from individuals who are unusually promising as prospective donors. For example, companies selling motorcycle insurance might find it attractive to offer very large cash payments or premium reductions for organ futures to motorcyclists, whose death rate is high and whose organs have a good probability of being harvestable in case of death since they are generally young and often die of head injuries. ${ }^{20}$ Or, if there were

19. Donation decisions for minor children would presumably be made on their behalf by their parents, since children are commonly covered by the same health insurance policy that covers the rest of the family.

20. The chance that the average motorcyclist will die in a vehicle accident during a given year is presently on the order of 1 in 1,000 (Insurance Institute for Highway Safety 1987). If all of the organs recoverable from a cadaver were on average worth $\$ 100,000$ collectively, and if organs could be recovered from one-third of all the persons killed in motorcycle accidents, then a futures contract for the average motorcyclist would be worth roughly $\$ 33$ (and more if the risk of death from other causes were factored in as well). If the total value of the organs harvestable from a single individual were $\$ 1,000,000$, then the futures contracts would be worth at least $\$ 333$. 
no limitations whatsoever on the solicitation of organ futures, some private firms or individuals might find it attractive to seek out, say, particularly rowdy motorcycle gangs and buy up organ futures from their members for cash. While such targeted solicitation activity would not necessarily be undesirable, it might give rise to at least two types of costs. First, the solicitation activity itself, if carried to an extreme, might appear distastefully sanguinary to a substantial segment of the public. Second, free entry could lead to a wasteful duplication of solicitation efforts. If these problems were to appear sufficiently serious, they would provide a further argument for limiting the right to solicit organ futures to general health insurers, which would probably offer premium reductions for organ futures based only on a few general factors, such as the insured's age.

With a futures market, any individual who had not sold a futures contract for their organs would presumably be deemed not to wish to have their organs made available for transplant. Thus the system need not be accompanied by a right to seek to purchase an individual's organs after he had died, whether from his estate or from his next of kin. Rather, a decedent's organs could be made purchasable only from a firm holding a valid futures contract that was executed by the deceased prior to his death. (It would be possible to permit an individual who had not signed a futures contract to designate in his will that his estate or next of kin would have the right to sell his organs upon his demise if the organs were harvestable. That is, his estate or next of kin would hold the future. But it might be appropriate to disallow this option: most individuals, being risk-averse, would presumably find it less attractive than selling a future while living, and permitting it might provide an added inducement to suicide for some individuals. $)^{21}$

Determining prices. The price (premium reduction) that insurance companies would pay for the future right to cadaveric organs would depend on the price that they could obtain for those organs at the time of removal. Since the health insurance business is reasonably competitive, presumably insurance companies would be able to take only a market rate of return for their efforts as intermediaries in such transactions; the rest of the (expected) price received by the insurance companies for the harvested organs would be passed through to their insureds in the premium reductions offered them.

21. If, upon an individual's death, the family objected to donation even though the individual had sold the rights to his organs, there would be an awkward problem. There are at least three possible responses: ignore the protest; permit the family to prevent the donation, but only upon paying the market value of the harvested organs; or respect the family's wishes (at least if they appear to feel very strongly on the matter) without requiring payment from them beyond refund, with interest, of the insurance premium reductions the family had received in the past. Although the first and second are the only responses that respect the transaction for sale of the organ futures, there might be considerable pressure to accept the third. Fortunately, anecdotal evidence suggests that it is almost unheard of for families to refuse consent when the deceased has clearly indicated a desire to donate their organs, so this should not be a common problem. 
How would the price for the harvested organs be determined? One possibility would be simply to establish a market in harvested organs, and to let the forces of supply and demand determine the ultimate price. This possibility is explored more carefully later in this article. The system would also be perfectly workable, however, if the price that an insurance company could obtain for a cadaveric organ were set administratively by the government rather than by market forces. For example, the government could simply provide that an insurance company (or its assignee) is entitled to receive no more than, say, $\$ 10,000$ for a kidney, $\$ 20,000$ for a heart, $\$ 15,000$ for a liver, and so forth. The insurance company would then set its offered premium reductions on the basis of these prices, discounted by the probability that the insured will die during the coming year and the probability that the insured's organs will be usable in case of death.

In particular, such a scheme could be employed in the context of the existing system for organ procurement. Under that system, organs are harvested and distributed through a network of roughly 70 regional organ procurement agencies that effectively have local monopolies on the supply of organs. These agencies are all nonprofit. They charge prices for the organs they procure that are, on average, just sufficient to cover their costs. At present these agencies do not charge, nor do they pay, any amount for the organ per se; rather, all charges are for the doctors' services and other personnel and equipment costs involved in harvesting and transporting the organ. If a futures market such as the one described here were implemented, these agencies could continue to function much as they do now; the only necessary change is that they would have to pay the administratively determined prices for organs to holders of the rights to those organs-prices that the agencies would then pass on to the recipients of the organs or their insurers along with the other costs of the transplant.

As an alternative, the market elements of such a scheme could be even further attenuated by requiring that the insurance companies resell the organ futures to the government immediately upon purchasing them at a price set by the government. The government could then simply allocate the organs through the existing organ procurement and distribution system without financial charge. Such a system would differ from a full government monopsony of the sort proposed by Schwindt and Vining only in that it would retain private insurance firms as administrators of the actual process of soliciting the organ futures, although this in itself might bring important advantages.

Regardless of the method employed to determine the price for harvested organs, a premium reduction system of the type described here would be practical only if that price were sufficiently high to make the value of the future rights to a policyholder's organs large enough to cover the costs to the insurers of administering the system (the insurers" "loading costs") and still have enough left over to provide a premium reduction to policyholders sufficient to catch their attention. Rough calculations can provide some perspective on the likelihood that this condition will be met. At present the average American has a chance of about 1 in 10,000 of 
dying during a given year under circumstances that would render his organs suitable for transplantation. ${ }^{22}$ If (for those decedents whose organs are harvestable) the average value of all the harvestable organs in a body were $\$ 100,000$ (that is, if this were the total amount for which the holder of the futures could sell the rights to the organs upon removal for transplanting), then the annual value of the futures for the average American would be roughly $\$ 10$. If the value of the organs when harvested were instead $\$ 1,000,000$, then the futures for a single year would be worth $\$ 100$. Although these are not large sums, amounts in this range-and especially toward the upper end of this range-could well be sufficient to cover insurers' loading costs and still provide a meaningful premium reduction. Moreover, higher premium reductions could be offered if it were possible (as seems likely) to identify substantial subgroups of the population, such as the elderly, whose organs would not be usable in any event and who could therefore be excluded from the group offered premium reductions.

Supply response. Of course, the principal motivation for adopting a payment scheme such as that just described would be to increase donation rates. A critical question, therefore, is whether it is reasonable to believe that donation rates would in fact increase substantially in response to the offer of insurance premium reductions.

As already noted, most individuals are evidently not in principle opposed to donation; presumably they fail to donate only because of inertia, mild doubts about their preferences, a slight distaste for considering the subject, or the inconvenience involved in completing or carrying a donor card. In this context, it is possible that a relatively modest financial incentive would improve donation rates substantially. The proffered premium reductions would serve to focus the attention of potential donors on the issue and would give them an incentive-or perhaps simply an excuse - for resolving their doubts in favor of donating. Put differently, the premium reductions might not serve so much to compensate people for giving up something of value to them as simply to make it worth their while to incur the transaction costs, both material and psychic, involved in making a decision to donate. In addition, and perhaps of equal or greater importance, because there would be a set of institutions - the insurance companies - with a strong incentive for soliciting donations, solicitation would presumably be far more extensive than at present.

On the other hand, there are several other considerations that might interfere with a strong supply response here.

Reduction of altruism. A common objection to providing compensation in contexts such as this is that it will drive out voluntarism - that is, that individuals

22. The U.S. population is roughly 240 million (U.S. Department of Commerce 1987: 74). It is estimated that between 17,000 and 26,000 people die annually under circumstances that make them potential organ donors (U.S. DHHS 1986: 35). 
who would otherwise be willing to donate out of a spirit of altruism will actually be less willing to donate if payment is offered. If this effect were serious and widespread, then the introduction of payment might produce little or no net overall increase in organ supply. The issue has been much debated in the context of blood donation (Titmuss 1971; Arrow 1975). The limited empirical evidence available in that context is ambiguous even as regards the supply of blood, and arguably does not carry over well to the context of organ donation in any case ${ }^{23}$ Thus, the most we can say at this point is that neither logic nor data permit us to conclude at this point whether a payment scheme such as the premium reduction plan described above would be counterproductive because of interference with altruistically motivated donations. Only experimentation is likely to provide clear answers.

Note, moreover, that whether the type of payment scheme described here would be perceived by prospective donors as inconsistent with their altruistic inclinations would presumably depend in considerable degree on the way in which those individuals frame the issue for themselves, and thus in turn on the way in which the choice is presented to them. For example, is the question whether the typical American would be willing to sell the rights to his organs for (say) $\$ 40$ per year? Or is it whether the typical American would be willing to pay an extra $\$ 40$ per year in health insurance premiums for the privilege of refusing to make his organs available to save several other persons' lives after he has died? Consider, in this connection, the approach suggested above for employees covered by group health policies at their workplace. As suggested there, it seems plausible that appeals to altruism, community spirit, and financial self-interest could all be combined in a fashion that would be complementary and effective in securing donations.

Note, too, that under an insurance premium reduction scheme organ donors could be permitted to designate that their premium reduction be donated to a charity of their choice rather than refunded to them personally. ${ }^{24}$

23. For a review of the literature on blood donor motivation and recruitment, see Oswalt (1977). Upton (1973) reports the results of what appears to be the best (though still very limited) empirical study on the subject. In that study, payment of $\$ 10$ for giving a pint of blood was offered to individuals in two groups: those who had regularly donated blood in the absence of payment, and those who had occasionally donated blood in the absence of payment. The offer of payment significantly reduced donation rates for the first group below a comparable sample not offered payment, while it slightly increased donation rates among individuals in the second group. Though this study does indicate that low levels of payment decrease donation rates for those otherwise strongly inclined to volunteer, it provides no clear indication of the likely consequences of a payment scheme for cadaver organs of the type outlined above, for several reasons. First, the results of the study are consistent with the conclusion that an offer of payment, even at only $\$ 10$ per pint, to the population at large would bring a substantial increase in overall donation rates. Second, donation rates in the first group may have fallen because of the low level of payment offered, which was surely below the opportunity cost of time and bother for many individuals in the group. Indeed, the offer of $\$ 10$ in payment may have been taken by many in this group as an indication that the social value of a pint of blood was only $\$ 10$, and hence it would not be worthwhile even from a social point of view - that is, even in the absence of compensationfor them to take the time to donate. Third, whereas for many individuals there is a very tangible opportunity cost in terms of time and effort to donating blood, the same is not true for donating the right to take their organs after death. Thus modest amounts of payment may produce a much larger response in the latter case than in the former.

24. Another reason offered by Titmuss (1971) for reliance on donations rather than purchases for 


\section{Hansmann - Markets for Human Organs}

Committing not to give. A further potential difficulty with a futures market for organs is that it might remove some people from the donor pool whose organs would be available under the current regime. As noted above, an individual who declines to accept a premium reduction or other payment for the future rights to his organs would presumably be deemed to wish not to make his organs available for transplant. Consequently, his family would not be free to decide to authorize donation upon his death. This is in contrast to the current regime in which, if an individual does not sign a donor card, it is still possible to prevail upon his family to donate his organs after his demise. If individuals in general are less inclined to donate their own organs than to agree to the donation of their deceased relatives' organs, which may be the case, these factors might diminish the advantage of the futures market approach relative to the current regime in terms of supply response. ${ }^{25}$ This problem is not confined to a market for organ futures. It arises with any approach, such as the mandatory choice approach described earlier, that confronts living individuals with a clear "yes or no" choice as to whether or not to be a donor upon their death.

Fear of doctors' incentives. A third factor that might detract from an individual's willingness to agree to sell the future rights to his organs is the fear that this will compromise the quality of health care he receives. Once the rights have been sold, there will be somebody with a financial interest in the individual's demise. People might suspect that this incentive could perhaps be brought to bear in some way on the doctors and hospitals responsible for treatment in life-threatening circumstances, rendering them less than zealous in sustaining life when the individual's organs appear harvestable. Though such fears would presumably be unrealistic under any properly regulated regime, they might not be easy to allay.

Net effects. In summary, it is not easy to predict what proportion of individuals would agree to donate in response to an offer of compensation for future rights to their organs. It is at least possible, however (though by no means certain), that

blood supplies was that the quality of commercially obtained blood was markedly lower than that of donated blood, particularly with respect to serum hepatitis (and, more recently, AIDS). (See also RoseAckerman 1985: 945-48.) This argument was apparently important in moving the American blood collection system from one in which (in 1965-1967) 80 percent of all blood was obtained from paid donors (Scott 1981: 191) to one in which virtually all whole blood is obtained from unpaid donors. It has been argued persuasively, however, that the quality of commercially obtained blood would not have been a problem if most states had not passed legislation prohibiting strict liability for diseases transmitted by transfused blood (Havighurst 1977). In any event, it is not clear that similar concerns about quality are applicable to "hard" organs such as kidneys and hearts, where the opportunity for moral hazard on the part of donors seems much smaller.

25. A variant on the insurance proposal outlined above would permit individuals to check one of three boxes on their insurance form: (1) donate and receive a premium reduction; (2) decline to donate; (3) make no decision one way or the other now, but leave the donation decision to the next of kin upon demise. If the latter option is provided, however, then it must be decided whether the next of kin or the deceased's estate should be able to receive compensation for the rights to the organs when they are removed. 
overall donation rates would be significantly higher under such an approach than they are, or could easily be brought to be, under the current regime.

Making decisions at the right time. An important advantage of the future contracting approach is that it would encourage decisions to donate when they are least problematic - namely, when they are made by the person whose own organs are involved and at a time when that person is healthy and has the opportunity to reflect at leisure on the matter and discuss it with family, friends, and advisors. In contrast, the existing system, and most of the reforms currently proposed for it, rely heavily on persuading an individual's family to agree to donate the individual's organs in the hours immediately following death. An unfortunate detriment of this approach is that it imposes considerable psychological pressure on both the family and the physician. Although it is sometimes suggested that putting a price on human organs would in some way be offensive to our values (an issue that will be explored in some detail below), it is important to keep in mind that any such moral difficulties with a futures market for organs must be compared with the morality of routinely inflicting distress on families by forcing them to make an emotionally difficult decision in the minutes and hours immediately following the death of a family member and subjecting them to substantial psychological and social pressure to make that decision in favor of donation. Indeed, it is arguably something of a misnomer to call the current organ procurement system "voluntary"; it might be more accurate simply to call it "uncompensated." (To be sure, health care professionals associated with the existing organ procurement system generally do not think of themselves as applying "social pressure" to bereaved families, but rather as "educating" them concerning the "opportunity" to donatee.g., Broznick $1988 .{ }^{26}$ Without some selective insensitivity along these lines and a strong sense of mission, the job would, of course, be much harder to do.)

Paying compensation versus changing tastes. For most individuals, any costs incurred in agreeing to donate their organs upon death are purely psychic; neither they nor their family and friends will experience any material disbenefit as a consequence of the decision. Such psychic costs - whether deriving from a belief that an intact corpse is necessary to achieve an afterlife, or simply from an aversion to the thought of dismemberment after death-are presumably subject to modification through education or changes in prevailing social mores. Thus it is possible that, over time, these costs could be mitigated and that a strong cultural norm affirmatively supporting organ donation could be developed, so that eventually nearly all members of society would experience a strong sense of gratification from donating and would clearly prefer to do so. (Obviously, many people feel this way

26. This is not to deny that there are many bereaved families that find solace and a redeeming sense of affirmative purpose in the opportunity to donate a relative's organs to save another person's life. It is only to suggest that there may be better ways to make this opportunity available. 


\section{Hansmann • Markets for Human Organs}

even now.) With a nearly universal cultural norm of this sort, compensation of any sort for donors could well be superfluous. A payment system would simply incur administrative costs to redistribute income without yielding any important benefits in terms of incentives. Other mechanisms for donation would then be preferable. For example, a true presumed consent system might be established under which organs would be routinely harvested without inquiry unless the deceased or next of kin took upon themselves the affirmative burden of making known their opposition.

It is possible that the present voluntary approach would be more effective than a payment scheme (such as the futures contracting approach described above) in building up such an ethic in the long run. If so, it might be reasonable not to adopt a payment scheme even if in the short run it would lead to a significantly higher rate of donation. This possibility deserves consideration. On the other hand, it is not at all clear that an ethic favoring donation could not be developed nearly as quickly, or even more quickly, in the presence of a modest payment scheme as it could without it. As suggested above, altruism and compensation need not be mutually exclusive, and the increased donation rate resulting from a payment scheme might itself be the fastest way to inure the populace to the concept of routine donation.

In any event, this argument applies only in the case of cadaveric organs; there will presumably always be more than merely psychic costs incurred by living organ donors, to whom we now turn.

\section{Markets for organs from living donors}

In theory, it would be much simpler to employ compensation in procuring organs-in particular, kidneys-from living donors than it would be in procuring cadaveric organs. In the past, payment has routinely been made to living donors for replenishable body products such as blood, sperm, skin, and hair (Scott 1981: 179-97). Strong controversy has arisen, however, over proposals to extend payment to kidneys. In fact, as observed earlier, the existing legal bans on organ sales seem primarily to have been inspired by such proposals.

Before assessing the objections that have been offered to purchasing organs from living donors, let us first consider the potential advantages.

Advantages. The chief advantage of using living donors for kidneys is that they offer a source of supply that could easily satisfy 100 percent of the foreseeable demand for transplants. Since there are only about 20,000 cadavers annually from which organs could potentially be harvested, we know that the supply of cadaveric organs is ultimately inelastic: there will be some point beyond which raising the price for organ futures (or pursuing any other strategy) will not appreciably increase supply. ${ }^{27}$ In contrast, the supply of kidneys from living donors is potentially

27. Prices might nevertheless be allowed to rise further, beyond the point where they bring additional 


\section{2}

Journal of Health Politics, Policy and Law

highly elastic, since most members of society could be donors and since as prices rise an ever-increasing percentage of the population would presumably be willing to donate. Widespread acquisition of kidneys from living donors therefore holds the promise of saving many lives and avoiding the substantial public expense and private agony of hemodialysis, which (aside from death) is the current alternative to a transplant.

Further, a large pool of living donors could lead to an important increase in the quality as well as the quantity of kidneys for transplant. The long-run success rate of kidney transplants has been closely correlated with the closeness of the match of tissue types between donor and recipient, and there is evidence that this correlation continues to hold even with the use of the new immunosuppressive drug cyclosporine (Cook and Terasaki 1988; but see also Najarian et al. 1988, who find such a correlation only for retransplants). With cadaveric organs, close tissue matching often cannot be achieved, particularly when there must be potentially deleterious transportation of organs over large distances. With a large pool of living donors, however, nearly universal close tissue matching could presumably be accomplished easily. Moreover, transplants from living donors eliminate the critical problems of timing that affect transplants of cadaveric organs, which require that a recipient be located and prepared and the transplant undertaken within hours of the (often unexpected) death of the donor.

Protecting the poor and improvident. For a large fraction of the population, selling a single kidney might be a reasonable decision at prices in a range that demand could support. Donation is evidently not highly hazardous to the donor's health: it has been estimated that the increased risk of death to a healthy 35-yearold from giving up a single kidney is about the same as that involved in driving a car sixteen miles every workday (Hamburger and Crosnier 1968). Many individuals willingly (and, most of us would probably conclude, reasonably) incur risks on this order to achieve savings in personal expenses or to obtain higher wages. Moreover, the fact that living individuals commonly donate kidneys to their relatives also suggests that such transactions are efficient in the economic sensethat is, that the organ is worth more to the recipient than it is to the donor-and thus that there will commonly be a price that will make both donor and recipient better off even in the absence of altruism.

It is often argued that the poor would be the principal sellers in a market for organs, and that therefore such a market would unacceptably exploit the poor for the benefit of the rich. The classical objection to this argument is, of course, that it is a perverse kind of paternalism that prohibits a class of transactions simply because the poor are likely to be the principal sellers, since the result of the pro-

increases in supply, in order to permit them to serve the rationing functions described later in this article. 
hibition is to leave the poor worse off by their own lights: any individual who would agree to sell would evidently rather have the money than have the slightly greater chance of avoiding the death or illness that would result from keeping the kidney. Thus, if society is not willing to give the poor sufficient assets so that they are not inclined to sell a kidney, then society should not refuse to let them sell one of the few assets they have (see, e.g., Andrews 1986; Radin 1987). And, after all, society does not prevent the poor from accepting pay for jobs such as coal mining and meatpacking that carry substantial risk of injury or death. Why should kidneys be different?

One might well conclude that kidneys are not in fact different, and that concerns about exploitation of the poor are misplaced here. But there are at least two reasons why selling kidneys might be thought of as distinguishable from selling one's labor to a meatpacking plant. For one thing, taking a job as a meatpacker is a day-byday decision that can be abandoned at any point that one thinks better of it. The sale of a kidney, in contrast, is a one-time act that is to a degree irreversible (although the possibility that a donor can get a transplant himself if his remaining kidney fails considerably reduces the degree of irreversibility). This means that the possibility of making a mistake in selling a kidney is much larger than the possibility of making a mistake in taking a job as a meatpacker. One might therefore be concerned that those individuals who would sell a kidney for commercial motives would (as compared with those who held ongoing jobs as meatpackers) contain a disproportionate number of individuals who had acted improvidentlywhether from lack of education or intellect or because circumstances made them temporarily and irrationally desperate - and who will come to regret their act (see Annas 1984). This might be reason enough to be concerned about permitting such sales even if all the unfortunate consequences were to be borne only by the individual seller. But those who sell a kidney and suffer health consequences later as a result are also disproportionately likely to be poor enough to have their subsequent medical care provided at public expense, so that some of the costs of the sale will be externalized to society at large.

Kidney sales may also be different from risky jobs in another sense. Suppose that the market-clearing price for kidneys from living donors would be high enough - say, $\$ 15,000$ - to be a serious temptation for a large number of poor people, but still not quite high enough to induce most poor persons to agree to sell. In such circumstances, many of the numerous poor who decide not to sell may feel themselves considerably worse off after making that decision than they would have if never faced with the decision at all. These individuals must, after all, live with the knowledge that they have refused to give something of themselves in return for funds that would be valuable to their family or other loved ones. Conventional economic analysis assumes that persons are always made better off by having more choices, but obviously that is not always true.

In any event, a market for kidneys from living donors would need to be regulated in some fashion to guard against improvident transactions. Presumably one would 


\section{4}

Journal of Health Politics, Policy and Law

not want a situation in which an unscrupulous doctor could induce a drunk to come in off the streets and yield up a kidney on the spot for \$50. Many forms of regulation would be possible. A rather heavily regulated regime, for example, might require that only federally licensed agencies be able to purchase kidneys (and might also require that the agencies be nonprofit); that there be a six-month waiting period between the time that the agreement of sale is entered into and the time the kidney is removed, at any time during which the transaction can be rescinded; that sellers must be at least 25 years of age, be examined by a physician and a social worker, and be approved by a consultative panel unconnected to the purchasing agency; and that the price not be below a mandated minimum sum. The question, then, is whether a commercial market for kidneys, even with an appropriate degree of regulation, would so harm the poor and improvident that such a market would be socially unacceptable. As a way to further test one's sensibilities here, consider a system under which the poor would be specifically prohibited from selling their organs - for example, by prohibiting purchases from individuals whose average income for the past three years was not at least 80 percent of median family income in the U.S. (thus cutting persons in the lower 40 percent of the income distribution out of the market).

Moreover, in considering distributive issues, it is important to recognize that the poor and improvident are quite disproportionately represented among those who suffer from kidney failure. If commercial purchase of kidneys from living donors would substantially increase the supply available for transplantation, these groups would therefore gain much of the benefit. The net result might therefore be quite progressive.

In sum, although the issues are difficult, it is not at all obvious that concern for the poor and improvident is a sufficient, or perhaps even a substantial, reason to reject purchases from living donors.

Commodification. It is frequently said-as in the statement from the federal task force report quoted above - that the commercial sale of human organs, and particularly organs from living donors, should be prohibited because it would tend to "commodify" them. It is difficult, however, to find a clear statement of precisely what is meant by commodification or why it is undesirable. ${ }^{28}$

28. One of the most recent efforts to give content to the notion of commodification appears in Radin (1987). Her analysis, which still leaves the general concept rather vague, becomes most substantive when she discusses the considerations that determine which transactions (at least at this stage of social development) are inappropriate for commodification-i.e., for commercial sales - and which are not (ibid.: 1909-14). These considerations are: improvident sales may make the seller worse off by his own estimation; certain things become "different" (and presumably inferior) things if they are bought and sold; and market transactions will tend to drive out nonmarket (and particularly altruistic) transactions, which for some goods have special value. Unfortunately, Radin offers very little analysis of the second and third considerations - which, as she notes, are closely related. 
Normative categories. Perhaps part of the underlying problem here is that as a society we tend to put most transactions into one of two distinct normative categories, which we might label "market transactions" and "nonmarket transactions." (Surely our culture in fact provides for many normative categories that differ on a number of dimensions; the simple two-category model presented here is only meant to be suggestive.) In market transactions, a good or service is exchanged for cash or other valuable consideration under circumstances in which both parties to the transaction enter into it in the expectation that they will personally be better off after the transaction than before. In nonmarket transactions, on the other hand, an individual's willingness to enter into the transaction is governed not by calculation of immediate personal gain but by a variety of other-regarding social mores or norms that the individual feels obliged to observe. Transactions involving the acquisition and care of automobiles tend to be put in the first category; transactions involving the acquisition and care of children tend to be put in the second category. For those transactions that are in the first category, social mores not only permit but in fact encourage individuals to be strongly self-seeking. Thus, if one sells one's used car to a stranger for less than its full market value, one is likely to be called a chump rather than an altruist. For those transactions that are in the second category, on the other hand, narrow calculations of personal advantage are considered inappropriate. If one tires of one's child it is not deemed acceptablemuch less praiseworthy - to stop giving it food or to sell it to the highest bidder.

One important characteristic that commonly distinguishes market transactions from nonmarket transactions is that the latter involve substantial external costs or benefits that cannot be internalized without excessive transaction costs. When selling a child, for example, there is a third party whose interests are heavily at stakenamely, the child himself. And, owing to such factors as the child's inability to borrow against future earnings and his imperfectly developed rationality, he is in no position to enter into transactions to protect his own interests. Parents must therefore be led to internalize a set of norms that induce them to provide care for their children whether or not they feel that what they get in return yields them adequate compensation. ${ }^{29}$

A second, closely related reason for using norms of right and obligation rather than market exchange to govern a set of transactions is that the cost of employing market mechanisms would be high relative to the value of the transactions involved. Thus, small transactions among individuals who interact frequently, such as those among friends, family, or workers within a firm (including those between managers and their subordinates), are often not mediated by markets but rather

29. Epstein (1985), focusing on legal rather than moral (i.e., informally enforced) restraints, makes the complementary argument that it is principally a desire to control negative externalities that underlies most efforts to outlaw the alienation of property through sale. (He does not, however, discuss the prohibition on sales of organs.) 


\section{Journal of Health Politics, Policy and Law}

by shared norms, since establishing prices for all such transactions would be unduly complex and time-consuming (see Coase 1937).

These two reasons for using morals rather than markets to govern any given set of transactions are fundamentally the same. The question in either case is ultimately whether it would be unduly costly to develop market mechanisms adequate to internalize to the decisionmakers involved all of the important costs and benefits of the transactions.

As has often been remarked, it is advantageous to assign as many transactions as possible to the category of market transactions since this "economizes" on morality. Where the "invisible hand" of the market works well in advancing social welfare, there is no reason to expend the substantial social effort necessary to develop and inculcate a (possibly very elaborate and perhaps rather rigid) set of norms to guide transactions.

Perhaps because our cognitive capacities are limited and because the social costs of inculcating norms are high, the psychological categories to which transactions are assigned tend to be broad and crude. It is not easy for us to consign one set of transactions to the nonmarket category and another seemingly closely related set of transactions to the market category. Moreover, substantial forces of inertia make it hard for us to rearrange our categories. Sometimes changes in technology or social institutions render it feasible to move a set of transactions from the second category to the first - that is, to use markets to handle transactions that were formerly guided by norms mandating a degree of altruism. But the process of undertaking such a shift may be difficult and highly contentious. If individuals were previously socialized to think it immoral to approach a set of transactions from a strongly self-regarding stance, then at first they are likely to find it deeply offensive to see the same transactions subjected only to the mores of the marketplace. Norms, by their nature, are not easily changed.

This inflexibility in our normative categories may help explain the reflexively negative moral response that commonly greets proposals for marketing human organs. There are a number of reasons why individuals might commonly be inclined to feel that giving up a body part to another individual belongs in the category of altruistic nonmarket transactions. There have previously been no markets here to which individuals might become accustomed. To those who have not thought closely about the nature of the risks involved, yielding up a vital organ such as a kidney while still alive may seem like the kind of life-threatening sacrifice (such as attempting to rescue a drowning person in heavy seas) that cannot easily be made the subject of market transactions and that have therefore always been governed primarily by other-regarding norms. For the past fifteen years, for good reasons or bad, our society has sought to delegitimate markets and encourage norms of altruism in the seemingly analogous area of blood donation. And for 25 years we have also been trying to encourage norms of altruism in the area of organ donation itself.

But initial resistance to shifting normative categories should not in itself be a sufficient reason for avoiding change. Transactions can be and have been recategor- 
ized when technological changes have made market mechanisms advantageous. For example, we are now quite accustomed to having proprietary institutions market nursing care for the elderly and matchmaking ("dating services") for the young. To take another example closer to the subject at hand, after several decades' experience our society has accepted a thriving market in human sperm brokered by proprietary firms. It would be easy to characterize such a market as deeply offensive to fundamental values involving paternity, sexual relations, responsibility for and identity with one's biological offspring, and the need to make children feel that their relationship with their parents transcends that of mere commodities. And evidently, there was substantial ethical resistance to this market when it was first introduced. Yet over time we have chosen not to so characterize such transactions, but rather to draw the symbolic lines between our normative categories elsewhere so that market transactions in human sperm are not perceived as undermining nonmarket norms in those areas where such norms continue to play a strong functional role.

On the other hand, it is costly to make people upset their received normative categories, and there is no point in doing so unless substantial benefits will result. Moreover, there may be some circumstances in which it is unusually difficult to acculturate individuals to distinguish between different categories of transactions for normative purposes.$^{30}$ For example, transplants of kidneys are least likely to be rejected by the recipient's body when there is a close match between the tissue types of the donor and the recipient. This means that transplants of kidneys from living donors within the same family are often the most successful. Most intrafamily transactions are and must remain nonmarket transactions rather than market transactions, however, and thus we are socialized to think that the calculus of the market is inappropriate among family members. Introducing market considerations into one very significant type of intrafamily transaction-that involving transfers of kidneys - might therefore strain the whole moral fabric of the families involved. You cannot extract a high price from your brother for one of your kidneys and then expect him to willingly provide you with extensive moral support for free while you go through your divorce.

Moreover, it may not even be possible to employ market transactions only for kidney transplants outside the family without putting severe strains on intrafamily relationships. For example, an individual might feel deeply resentful if subjected to moral pressure to donate a kidney to a family member without compensation when a substantial payment would be forthcoming if the organ were transplanted outside the family. ${ }^{31}$ In short, it may be very difficult here to draw lines, whether

30. This problem is apparently what people have in mind when they object to employing markets for a given class of transactions not because market allocation would be inappropriate for those transactions themselves, but for "symbolic" reasons. For discussion in the context of markets for babies for adoption, see Posner (1987: 70-71) and Cass (1987).

31. An analogous problem arises for daughters or sons who have a particular skill - for example, 
between transfers of kidneys within the family and other types of intrafamily transfers or between intrafamily and interfamily transfers of kidneys.

It follows that if most kidneys from living donors had to come from family members, it might be best not to try to develop market transactions for kidneys, even among strangers. The rapid development of immunosuppressive drugs, however, has made transplants among unrelated individuals increasingly feasible. As this development reduces the need for intrafamily donations, the costs of using market transactions among living kidney donors - in the form of moral strain on family relationships in general, and perhaps also in the form of reduced intrafamily kidney donations - may decline (indeed, it may already have declined ${ }^{32}$ ) to the point where they no longer need be considered important.

In any event, it is understandable that, whatever the ultimate merits of a market for human organs, the initial reaction to a proposal for such a market is likely to be one of strong moral opposition. NOTA's proscription of market transactions in organs presumably reflects precisely this type of reaction. Ironically, but perhaps expectably, this ban has been enacted just at the time when such a policy is probably becoming anachronistic, not only for cadaveric organs but perhaps for organs from living donors as well. Before markets for organs were feasible, there was little incentive to outlaw them. Now that such markets seem feasible, the idea of having them offends the norms that developed in their absence.

Altruism as a good in itself. It is sometimes argued that, at least in some circumstances, altruistic transactions have value in themselves to donors as well as recipients, that commercial transactions will tend to drive out altruistic ones, and that therefore commercial transactions should be forbidden in such circumstances (e.g., Titmuss 1971; Radin 1987). But even if we accept that (perhaps for reasons rooted in our heredity) we have a need for altruistic relationships and that commercial sales and altruism are inconsistent, it remains for us to determine for which transactions this is sufficiently important to support the proscription of sales. If such considerations do not justify outlawing a commercial market in care for one's elderly parents - and we evidently feel it does not-then why should they justify outlawing sale of the rights to one's organs, even after death? Other considerations, such as those discussed earlier here, still seem necessary to draw the line between those transactions suitable to commercialize and those which are most suitably used to satisfy our needs for altruism.

\section{Too many organs?}

A final, perverse problem that could arise from an effort to employ market incentives to procure organs-whether from living donors or from cadavers - is

medicine or law-that is in demand by other members of the family, who apply pressure for the contribution of professional time that could be charged for on the market.

32. For somewhat conflicting evidence on this point, see Cook and Terasaki (1988) and Najarian et al. (1988). 
that such an approach might be so much more effective than the existing voluntary donation system that it would put extreme pressure on current methods for rationing transplantable organs. Transplants are extremely expensive: a heart transplant costs between $\$ 60,000$ and $\$ 110,000$ and a liver transplant costs between $\$ 70,000$ and $\$ 240,000$ (U.S. DHHS 1986: 99). Most of these costs are covered by public funds. Nevertheless, at present there are no policies to limit the number of transplants that are performed in the United States. Rather, an effort is made to transplant all organs that are donated. Thus, the rate of donations is the only limit on the number of transplants performed. Because potential recipients considerably outnumber donors, current policy seeks to ration the existing supply to those individuals who will benefit the most from a transplant—such as those who are relatively young, otherwise healthy, and potentially productive (Robertson 1987: 81). Consequently it is arguable that, despite their high cost, most or all of the organ transplants that are performed are justified in the sense that social benefits exceed social costs (although there seem to have been no careful efforts to study the matter).

But if the supply of organs were to increase substantially, society might be faced with a difficult choice. On the one hand, the policy of transplanting all available organs could be maintained. But this might require devoting an extremely large amount of society's resources to transplants. And with a larger supply of organs, an increasing number of recipients would come from among those who would have only a small chance of gaining from the transplant an appreciable number of years of productive life..$^{33}$ On the other hand, the government could decide that there are some individuals for whom it will not cover the expense of a transplant even if an organ is available for which there is no other use. Either course might be painful. So long as the number of organs available for transplantation is severely limited, these alternatives need not be confronted. Thus, in a sense it is convenient to have a severe limit on the availability of organs. Perhaps part of the reason that our society has not more aggressively sought ways to increase the supply of organsincluding, perhaps, market incentive schemes such as the kind suggested aboveis that we are not eager to confront the extremely difficult and expensive problems of allocation that would result if we were successful. ${ }^{34}$

Of course, markets are one potential mechanism for dealing with these problems of allocation, and that is our next topic.

\section{Markets for Allocating Organs}

So far we have been discussing a market system simply as a means of encouraging a larger supply of organs. It remains to ask whether a market could also

33. As Schuck (1989) observes, the federally funded kidney dialysis program is already encountering this difficulty.

34. See Calabresi and Bobbitt (1978) for a sophisticated discussion of other respects in which our mechanisms for producing and allocating vital resources, including human organs, are sometimes structured in order to avoid or obscure difficult social choices among strong competing values. 
be employed as a means of rationing the supply of organs among potential recipients. ${ }^{35}$

\section{Distributional consequences}

A common objection to establishing a market for organs is that it would have the undesirable consequence of channeling most organs to the rich and making them completely unavailable to the poor. There are, however, several reasons to believe that a market approach would not appreciably disbenefit the poor relative to the current system, and that it might in fact considerably improve their access to transplants.

First, and most important, individuals rarely pay for transplants directly out of their own pockets; most transplants are paid for by public and private health insurance plans, and this practice will presumably continue. Thus the distributional issue here, as elsewhere in health care, concerns marketing health insurance, not marketing transplants themselves. Second, doctors' services, hospital services, and drugs will probably always account for most of the cost of a transplant; adding a charge for the organs themselves is unlikely to lead to a quantum increase in the total cost. Thus, those who would be unable to pay for a transplant if there were a charge for the organ would generally also be unable to pay for it without such a charge. Moreover, it is not clear why distributional concerns call for the organs themselves to be allocated on a nonmarket basis while these other items are priced on a commercial basis. Third, distributional issues must be judged relative to the status quo. For example, although there is a disproportionately large number of poor blacks among those individuals who need transplants (U.S. DHHS 1986: 92), anecdotal evidence suggests that the current system of allocating organs through administrative discretion exhibits a substantial bias toward distributing the available scarce supply to prosperous white males. (Oddly, good demographic data on socioeconomic variables such as the income, education, or occupation of organ transplant recipients seem to be unavailable.) Allocation by price, with insurance plans as payers, might actually lead to a more egalitarian distribution. Fourth, even if relatively prosperous individuals are going to end up with most of the organs in any case, as they do under the current nonmarket system, then progressivity might at least be served by making these individuals pay for the organs they receive (whether directly or through increased health insurance pre-

35. In theory, markets could be used to ration demand, but not to encourage supply. The current system of voluntary donation (or one of the proposed variants on that system, such as presumed consent) could be used to procure organs, which would then be collected by government agencies or nonprofit firms (such as the existing organ procurement agencies) and then sold to the highest bidders. The resulting profits could then be used to subsidize any desired aspect of the health care system, including transplants or transplant research. The current system for collecting whole blood has something of this character - the Red Cross, which is the major supplier, collects blood from uncompensated donors and then sells the blood at prices that evidently yield a net surplus (Zimmerman 1981). 
miums), and then distributing the resulting funds to a more representative crosssection of the public by compensating organ donors.

\section{Market pricing in the context of insurance}

A market approach to allocating supply could potentially yield the same types of efficiency advantages here as it does elsewhere. First, it could help assure that the available organs go to those individuals for whom they have the most value. Second, it could take the pressure off the existing administrative system of allocation, and avoid any biases inherent in that system. Third, it could help equate aggregate supply and aggregate demand-that is, it could help assure that the number of organs harvested and transplanted is that which equates the disbenefit to the marginal donor with the benefit to the marginal recipient. The important question is whether these potential benefits could be realized within the existing system of health care finance, which is characterized by nearly universal health insurance and in which insurance plans would therefore be the principal participants bidding in the market.

At present, government insurance programs pay for nearly all kidney transplants (Schuck 1989). As a consequence, there is presumably little role for market forces in allocating kidneys. The government, which is in the position of a monopsonist, would in any event establish the price for harvested kidneys and allocate the kidneys thus procured, simply as a matter of administrative discretion. However, the government's role in other types of transplants is much smaller. Most heart transplants, for example, have been paid for out of private insurance; public insurance programs have played only a minor role, although that role is now growing (Evans 1987: 73; Schuck 1989). Since there are a number of competing private health insurers, a market system of allocation therefore holds more promise for organs other than kidneys.

Private insurers would presumably treat the cost of an organ the same way they do the other costs of organ transplants or the costs of any other form of medical care covered by their policies. The insurers' overall demand for transplants - and hence the market price for organs-would ultimately be determined by the amounts of coverage that individuals were willing to purchase at premiums sufficient to cover the insurers' costs. This approach has the advantage that the number and nature of the transplants to be undertaken and the aggregate resources to be devoted to them would be determined, in advance of medical crisis, by individuals or their representatives (particularly unions and employers responsible for health insurance plans) in a context that permits them to reflect calmly on the amount of resources they choose to devote to health care in the aggregate and the amount they choose to devote to transplants in particular as opposed to other types of medical care. This is not to suggest that the market can be expected to work as well for organ transplants as it does for oranges and machine screws. But it should work roughly as well for transplants as it does for other forms of costly medical 


\section{2}

Journal of Health Politics, Policy and Law

care. If, as it appears, we are willing to continue to experiment with a market approach to medical care in general in this country-and it is still unclear what that system will look like in the long run, and how it will perform-then it is not clear why we should adopt a nonmarket regime for transplants. ${ }^{36}$

\section{Would market allocation raise the cost of transplants?}

It is sometimes objected that establishing a price of any kind for harvested organs, and particularly a market-determined price, would have the unfortunate effect of considerably raising the price of organ transplants, which is already extremely high. This might be true so far as the private costs of transplants are concerned (that is, the out-of-pocket expense to the recipients or their insurers). But these private costs would be much higher than the social cost (that is, the actual cost to society as a whole of foregone goods and services incurred as a result of undertaking the transplants). The reason for this is that most of the price paid for the organs themselves would ultimately go into the hands of the individuals selling the organs (or the organ futures), and thus would simply involve redistribution among members of society rather than a true social cost. Furthermore, the net amount of redistribution involved might be small. If organs were obtained through a futures market operated by health insurers, then the payments for the organs, in the form of reduced insurance premiums, would be broadly spread through the population. Since the prices paid for organs would largely be passed back to the public in the form of higher health insurance premiums (or, in the case of public health insurance, higher taxes), for most people the net financial effect might be largely a wash. And, as suggested earlier, any net redistribution that did result would probably be progressive.

Indeed, to the extent that a market pricing scheme would lead to a more efficient distribution of organs among potential recipients or to a more efficient overall level of transplants, the result of market pricing would be to reduce the social costs of transplants rather than raise them.

\section{Property rights under the existing system}

Any market-oriented approach to allocating organs should be evaluated not in the abstract but in comparison to the available alternatives. In particular, such an approach needs to be compared to the allocation system currently in place.

The existing allocation system already provides for property rights of a sort in human organs. In effect, rights to most harvested organs are now governed by something like a "rule of capture" under which the organs effectively become the

36. For an insightful account of the way one insurer, Massachusetts Blue Cross/Blue Shield, has dealt with payment for liver transplants (in the context of a heavy state regulation of transplants), see Havighurst and King (1986). 
property of the hospital that harvests them and/or the local organ procurement agency. Since the organs themselves cannot be sold, the only way these institutions can benefit from them is to transplant them themselves and thus create professionally and financially rewarding activity for the surgeons and other health care professionals associated with these institutions. This naturally creates an incentive for hoarding organs locally rather than sharing them with transplant centers elsewhere that might have greater need of them. In short, there is already a market of sorts for human organs, but one in which sale of an organ must be tied to sale of the physician and hospital services involved in its transplantation. (It follows that extending the diagnosis-related group, or DRG, system of payment ${ }^{37}$ to organ transplant operations could well be construed as a violation of NOTA, since the difference between the DRG payment that a hospital received and the hospital's actual cost for the operation would effectively be a payment to the hospital for the organ itself. The larger this difference, the stronger the hospital's incentive to secure organs for transplantation would be.)

Allowing health insurers to establish property rights in harvested organs would facilitate the allocation of organs on a national basis rather than a largely local one. Such a policy would also, of course, be likely at first to be seen as threatening by the health care professionals involved with existing organ procurement agencies and transplant centers. In the long run, however, the result might be a significantly larger overall level of transplant activity, a more rational system of organ allocation, and less pressure on physicians and other health care professionals to devote their energies to persuading individuals to donate organs and to making difficult decisions as to who is to receive them. Thus, nearly everyone involved with the current system might stand to benefit in the end.

\section{Conclusion}

As our technology and our social institutions have developed, we have found it possible and desirable to use various types of market mechanisms to allocate an increasing range of goods and services that were formerly allocated through the family, charitable institutions, or the state. We are now arguably reaching that stage with human organs for transplantation. It would be foolish to suggest that the market offers a magic solution to the many agonizingly difficult issues involved in organ transplantation. But given the disabilities of the current system for obtaining and allocating organs and the improvements that are at least potentially available by permitting appropriate forms of compensation, the present blanket

37. Under the DRG system, a hospital receives a fixed payment of a given amount for all treatments of a given type, regardless of the actual cost incurred by the hospital in treating any particular individual patient. 


\section{4} Journal of Health Politics, Policy and Law

prohibition on any form of payment seems extreme. Consequently, there is a good case for reforming federal and state law to permit judicious experimentation with suitably regulated markets both to procure and to distribute human organs.

\section{References}

Andrews, L. 1986. My Body, My Property. Hastings Center Report 16 (5): 25-38.

Annas, G. 1984. Life, Liberty and the Pursuit of Organ Sales. Hastings Center Report 14 (1): 22-23.

Arrow, K. 1975. Gifts and Exchanges. In Altruism, Morality, and Economic Theory, ed. E. Phelps. New York: Russel-Sage Foundation.

Boston University Law Review. 1987. Adoption and the Market Theory. 67: 59-175.

Brams, M. 1977. Transplantable Human Organs: Should Their Sale Be Authorized by State Statutes? American Journal of Law and Medicine 3 (2): 183-95.

Broznick, B. 1988. Organ Procurement: Fulfilling a Need. Transplantation Proceedings 20 (1, Supp. 1): 1010.

Calabresi, G., and P. Bobbitt. 1978. Tragic Choices. New York: Norton.

Cass, R. 1987. Coping With Life, Law, and Markets: A Comment on Posner and the Lawand-Economics Debate. Boston University Law Review 67: 73-97.

Coase, R. 1937. The Nature of the Firm. Economica 4: 386-405.

Cook, B., and P. Terasaki. 1988. Cyclosporine A and Histocompatibility in Kidney Transplantation. Transplantation Proceedings 20 (3, Supp. 2): 244-48.

Dukeminier, J., and D. Sanders. 1968. Organ Transplantation: A Proposal for Routine Salvaging of Cadaver Organs. New England Journal of Medicine 279 (8): 413-19.

Epstein, R. 1985. Why Restrain Alienation? Columbia Law Review 85 (5): 970-90.

Evans, R. 1987. The Economics of Heart Transplantation. Circulation 75 (1): 63-75.

Gallup Organization, Inc. 1985. The U.S. Attitudes Toward Organ Transplantations/Organ Donation. Princeton, NJ: Gallup.

Gerson, B. 1987. Refining the Law of Organ Donation: Lessons from the French Law of Presumed Consent. New York University Journal of International Law and Politics 19: 1013.

Hamburger, J., and J. Crosnier. 1968. Moral and Ethical Problems in Transplantation. In Human Transplantation, ed. F. Rapaport and J. Dausset. New York: Grune and Stratton.

Havighurst, C. 1977. Legal Responses to the Problem of Poor-Quality Blood. In Blood Policy: Issues and Alternatives, ed. D. Johnson. Washington, DC: American Enterprise Institute.

Havighurst, C., and N. King. 1986. Liver Transplantation in Massachusetts: Public Policymaking as Morality Play. Indiana Law Review 19 (4): 955-87.

Insurance Institute for Highway Safety. 1987. IIHS Facts 1987: Motorcycles. Washington, DC: IIHS.

Katz, B. 1984. Increasing the Supply of Human Organs for Transplantation: A Proposal for a System of Mandated Choice. Beverly Hills Bar Association Journal 18 (Summer): 152-67.

Koop, C. 1984. Increasing the Supply of Organs for Transplantation. Public Health Report 98 (6): $566-72$. 


\section{Hansmann • Markets for Human Organs}

Landes, E., and R. Posner. 1978. The Economics of the Baby Shortage. Journal of Legal Studies 7 (2): 323-48.

Lee, P. 1986. The Organ Supply Dilemma: Acute Responses to a Chronic Shortage. Columbia Journal of Law and Social Problems 20 (4): 363-407.

Michigan Law Review. The Sale of Human Body Parts. 72 (6): 1182-264.

Najarian, J., R. Migliori, R. Simmons, N. Ascher, W. Payne, D. Dunn, D. Sutherland, and D. Fryd. 1988. Effects of HLA Matching in Cadaver Renal Transplants. Transplantation Proceedings 20 (3, Supp. 3): 249-56.

Oswalt, R. 1977. A Review of Blood Donor Motivation and Recruitment. Transfusion 17 (2): 124-35.

Posner, R. 1987. The Regulation of the Market in Adoptions. Boston University Law Review 67: 59-72.

Prichard, S. 1984. A Market for Babies? University of Toronto Law Journal 34 (3): $341-$ 57.

Radin, M. 1987. Market-Inalienability. Harvard Law Review 100 (8): 1849-937.

Robertson, J. 1987. Supply and Distribution of Hearts for Transplantation: Legal, Ethical and Policy Issues. Circulation 75 (1): 77-87.

Rose-Ackerman, S. 1985. Inalienability and the Theory of Property Rights. Columbia Law Review 85 (5): 931-69.

Schuck, P. H. 1989. The Role of Government in Paying for Organ Transplants. Elsewhere in this volume.

Schwindt, R., and A. Vining. 1986. Proposal for a Future Delivery Market for Transplant Organs. Journal of Health Politics, Policy and Law 11 (2): 483-500.

Scott, R. 1981. The Body as Property. New York: Viking Press.

Stason, E. 1968. The Uniform Anatomical Gift Act. Business Lawyer 23 (4): 919-29.

Titmuss, R. 1971. The Gift Relationship. New York: Pantheon Books.

Upton, W., III. 1973. Altruism, Attribution and Intrinsic Motivation in the Recruitment of Blood Donors. In Selected Readings in Donor Motivation and Recruitment, volume II, ed. American Red Cross.

U.S. Department of Commerce. Bureau of the Census. 1987. Statistical Abstracts of the United States: 1988. Washington, DC: U.S. Government Printing Office.

U.S. Department of Health and Human Services. 1986. Report of the Task Force on Organ Transplantation: Issues and Recommendations. Rockville, MD: DHHS.

Vestal, A., R. Jaber, and W. Shoemaker. 1954. Medico-Legal Aspects of Tissue Homotransplantation. University of Detroit Law Journal 18 (3): 271-94.

Virginia Law Review. 1985. Regulating the Sale of Human Organs. 71 (6): 1015-38.

Zimmerman, D. 1981. The Red Cross: Banking on Charity. San Francisco Examiner Magazine, 26 July, pp. 16-21. 